FACULDADE DE CIÊNCIAS ECONÔMICAS DA UFRGS Análise
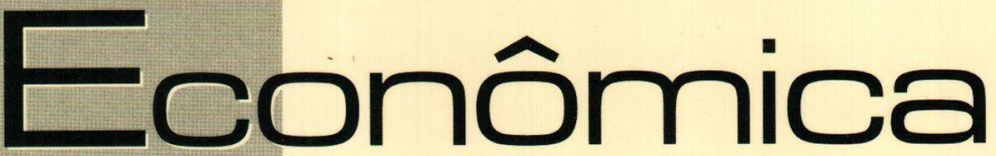

FLUTUACÃO CAMBIAL E METAS INFLACIONÁRIAS EM

ECONOMIAS EMERGENTES

OTAVIANO CANUTO E MárCIO HOLLAND

ATEORIA DE FORMACĆOO DE PRECOS E A TEORIA DOS PREÇOS DE

PRODUCAO

LOIZALBERTO ESTEVES

AECONOMIA EVOLUCIONISTA: UM CAPITULOSISTEMMICO DA

TEORIA ECONOMICA?

HUGOE. A. DA GAMACERQUEIRA

RELAÇ̃O INFLAÇÃO-PRODUTO NO BRASIL NO PERIODO PÓS-

REAL

MARCOSC. HOLANDA

DIVIIDA PÚBLICAMOBILLÍRIA FEDERAL BRASILEIRA: HISTÓRIA RECENTE E PERSPECTIVAS EXPLOSIVAS

ROGÉRIO MEURER E ROBERT WAYNE SAMOHYI

A CEPAL EA INTEGRACÃO REGIONAL LATINO-AMERICANA JACQUELINE A. HERNANDEZ HAFFNER

POPPER, HAYEK EA (IM)POSSIBILIDADE DE PREDIÇŌES ESPECIFICAS EM CIEENCIAS SOCIAIS

BRENA PAULA MAGNO FERNANDEZ

DINÂMICA RECENTE DO PROCESSO DE INCUBACG̃O DE

EMPRESAS DE BASE TECNOLOGICA NO BRASIL

EDUARDO GONÇALVES

TRIBUTACĀO COM SACRIF́CIO EQUUITATIVO: O CASO DO IMPOSTO DE RENDA PESSOA FISICA

STEFANO FLORISSI E EDUARDO PONTUAL RIBEIRO

A NOVATEORIA DO IMPÉRIOE AS VELHAS TEORIAS DO

IMPERIALISMO

GENTIL CORAZZA

Ô ABREALAS - A NOVA INSERÇÃO DO BRASIL NA ECONOMIA MUNDIAL

EMLLLANO LUIS KLEN

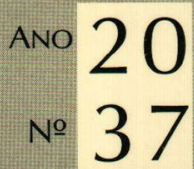

Março, 2002 
UNIVERSIDADE FEDERAL DO RIO GRANDE DO SUL

Reitora: Profa. Wrana Maria Panizzi

FACULDADE DE CIÊNCIAS ECONÔMICAS

Diretor: Prof. Pedro Cézar Dutra Fonseca

CENTRO DE. ESTUDOS E PESQUISAS ECONÔMICAS

Diretor: Prof. Gentil Corazza

DEPARTAMENTO DE CIÊNCIAS ECONÔMICAS

Chefe: Prof. Luiz Alberto Oliveira Ribeiro de Miranda

DAPARTAMENTO DE CIÊNCIAS CONTÁBEIS E ATUARIAIS

Chefe: João Marcos Leão da Rocha

CURSO DE PÓS-GRADUAÇÃO EM ECONOMIA

Coordenador: Prof. Eduardo Pontual Ribeiro

CURSO DE PÓS-GRADUAÇÃO EM ECONOMIA RURAL

Coordenador: Prof Jalcione Almeida

CONSELHO EDITORIAL: Carlos G. A. Mielitz Netto (UFRGS), Eduardo A. Maldonado Filho (UFRGS), Eduardo P. Ribeiro (UFRGS), Eleutério F. S. Prado (USP), Eugênio Lagemann (UFRGS), Fernando Cardim de Carvalho (UFRJ), Fernando Ferrari Filho (UFRGS), Fernando de Holanda Barbosa (FGV/RJ), Flávio Vasconcellos Comim (UFRGS), Gentil Corazza (UFRGS), Giácomo Balbinotto Neto (UFRGS), Gustavo Franco (PUC/RJ), Jan A. Kregel (Università di Bologna e John Hopkins University), João Rogério Sanson (UFSC), Joaquim Pinto de Andrade (UnB), Jorge Paulo Araújo (UFRGS), Juan H. Moldau (USP), Marcelo S. Portugal (UFRGS), Maria Alice L.ahorgue (UFRGS), Paul Davidson (University of Tennessee), Paulo Dabdab Waquil (UFRGS), Pedro Cézar Dutra Fonseca (UFRGS), Philip Arestis (South Bank University), Roberto C. Moraes (UFRGS), Ronald Otto Hillbrecht (UFRGS), Sabino da Silva Porto Jr. (UFRGS), Stefano Florissi (UFRGS), Werner Baer (Univ, of Illinois at Urbana-Champaign).

COMISSÃO EDITORIAL: Eduardo Augusto Maldonado Filho, Fernando Ferrari Filho, Gentil Corazza, Marcelo Savino Portugal, Paulo Dabdab Waquil; Roberto Camps Moraes.

EDITOR: Fernando Ferrari Filho

EDITOR ADJUNTO: Gentil Corrazza

SECRETÁRIA: Vanessa Hoffmann de Quadros

REVISÃO DE TEXTOS: Vanete Ricacheski

FUNDADOR: Prof. Antônio Carlos Santos Rosa

Os materiais publicados na revista Análise Econômica são da exclusiva responsabilidade dos autores. É permitida a reprodução total ou parcial dos trabalhos, desde que seja citada a fonte. Aceita-se permuta com revistas congêneres. Aceitam-se, também, livros para divulgação, elaboração de resenhas e recensões. Toda correspondência, material para publicação (vide normas na terceira capa), assinaturas e permutas devem ser dirigidos ao seguinte destinatário:

PROF FERNANDO FERRARI FILHO

Revista Análise Econômica - Av. João Pessoa, 52 CEP 90040-000 PORTO ALEGRE - RS, BRASIL Telefones: (051) 316-3348 e 316-3440 - Fax: (051) 316-3990

E-mail: rae@vortex ufrgs br

Análise Econômica

Ano 20, n 37 , março, 2002 - Porto Alegre

Faculdade de Ciências Econômicas, UFRGS, 2000

Periodicidade semestral, março e setembro.

1. Teoria Econômica - Desenvolvimento Regional Economia Agrícola - Pesquisa Teórica e Aplicada -

Periódicos. I. Brasil.

Faculdade de Ciências Econômicas,

Universidade Federal do Rio Grande do Sul.

CDD 330.05

CDU 33 (81) (05) 


\title{
Dívida pública mobiliária federal brasileira: história recente e perspectivas explosivas ${ }^{1}$
}

\author{
Roberto Meurer ${ }^{2}$ e Robert Wayne Samohyl
}

\begin{abstract}
Resumo: $\mathrm{O}$ artigo discute a dívida pública mobiliária federal e seus determinantes. Deste 1992, o débito cresceu cerca de $4.000 \%$, para $45 \%$ do PIB, e continua crescendo, principalmente em função das elevadas taxas de juros. A política de esterilização da entrada de moeda estrangeira foi um importante fator de expansão até 1998, quando o regime cambial foi modificado para flutuante. Um modelo de evolução da dívida é estimado e diferentes cenários são analisados para um horizonte de 10 anos. A taxa de juros elevada é a componente mais sensivel da evolução da dívida federal. $\mathrm{O}$ artigo conclui que a dívida cresce rapidamente e há dificuldades para reverter esta tendência no curto prazo. $O$ valor de futuras privatizações ou superávits primários é relativamente pequeno em termos do valor da dívida e como instrumentos de política econômica são, por isso, inócuos.
\end{abstract}

Palavras-chave: dívida pública mobiliária, taxa real de juros, superávits primários.

Abstract: The article discusses the Brazilian domestic federal debt, and its immediate determinants. Since 1992 the debt has grown about $400 \%$ to $45 \%$ of GDP, and continues growing due mainly to high interest rates. A policy of sterilization of the influx of foreign exchange was an important expansion factor until 1998, when the exchange regime was changed to a floating one. A model of the debt is estimated and different scenarios for projections are evaluated for a 10 year period. The high interest rate is the most sensitive component to the evolution of the federal debt. The article concludes that the debt has grown fast, and that this tendency is difficult to be turned around in the near future. The value of future privatizations or budget surpluses is relatively small in terms of the debt and as policy instruments are therefore innocuous.

Key words: federal public debt, real interest rate, primary budget surplus.

\footnotetext{
${ }^{1}$ Agradecemos pelos comentários e sugestões recebidos do Professor Roberto Camps de Moraes a uma versão anterior deste trabalho, apresentada no III Encontro de Economia da Região Sul, realizado em setembro de 2000 em Porto Alegre e de um parecerista desta Revista. Os erros remanescentes são de responsabilidade dos autores.

${ }^{2}$ Departamento de Economia, Universidade Federal de Santa Catarina.

${ }^{3}$ Departamento de Engenharia de Produção e Sistemas, Universidade Federal de Santa Catarina.
} 


\section{Introdução}

A dívida pública mobiliária federal brasileira fora do Banco Central cresce muito no período compreendido entre 1992 e 2000 , de $\mathrm{R} \$$ 99 bilhões para R $\$ 516$ bilhões $^{4}$. Também em comparação com o PIB, a divida cresce consideravelmente: de $3 \%$ no final de 1991 para $45 \%$ em dezembro de 2000. Neste período a economia brasileira apresenta algumas alteraçōes importantes: a) de 1992 a junho de 1994 a taxa de inflação passou de $20 \%$ para $50 \%$ ao mês e a variação cambial seguia aproximadamente estes índices; b) a partir de julho de 1994, com a reforma monetária do Plano Real, há uma redução drástica da inflação, que foi de aproximadamente $11,4 \%$ ao ano entre agosto de $1994 \mathrm{e}$ dezembro de 2000 . O câmbio é aproximadamente fixo até final de 1998, mesmo quando opera formalmente em um regime de bandas; c) em janeiro de 1999, o regime cambial passa a flutuante ao mesmo tempo em que ocorre uma expressiva desvalorização da moeda brasileira. No final de 1994, a balança comercial passou de constantemente positiva para cronicamente deficitária, o que é revertido somente a partir de 1999, com uma grande redução dos déficits comerciais. Com a manutenção dos déficits da balança de serviços, existe um considerável aumento do déficit em transaçōes correntes. A entrada de capitais externos, investimentos diretos e de portfólio, entretanto, compensou os déficits de transações correntes e ainda possibilitou a acumulação de reservas internacionais em alguns períodos que, entretanto, se mostraram voláteis quando ocorreram turbulências nos mercados financeiros mundiais. Alguns aspectos da evolução da dívida podem ser observados na tabela 1. Chama atenção nesse conjunto de dados a baixíssima relação dívida/PIB ao final de 1991, o que é influenciado pelo fato de grande parte da dívida mobiliária ter sido transformada compulsoriamente em "valores à ordem do Banco Central" no Plano Collor, em 1990. A liberação desses valores, que gerou aumentos da dívida mobiliária, foi encerrado em agosto de 1992.

${ }^{4}$ US $\$ 1=R \$ 1,9554$ em 31 de dezembro de 2000.

5 Todos os valores utilizados neste trabalho estão expressos em reais constantes de dezembro de 2000 , deflacionados pelo IGP-DI. Os valores foram obtidos em diferentes números do Boletim do Banco Central do Brasil e das Notas para a Imprensa divulgadas mensalmente. 
Tabela I - Dívida mobiliária federal: Relação com o PIB (\%) e indexadores (\% do total) - 1991 a 2000 - Valores em dezembro de cada ano

\begin{tabular}{|c|c|c|c|c|c|c|c|c|c|c|}
\hline & 1991 & 1992 & 1993 & 1994 & 1995 & 1996 & 1997 & 1998 & 1999 & 2000 \\
\hline Dívida/PIB & 3 & 8,9 & 9,2 & 8,7 & 11,9 & 18,1 & 28,4 & 35 & 39,7 & 45,2 \\
\hline Câmbio & 11,5 & 3 & 17,3 & 8,3 & 5,3 & 9,4 & 15,4 & 21 & 24,2 & 21,7 \\
\hline Over/Selic & 67,2 & 9 & 3,8 & 16 & 37,8 & 18,6 & 34,8 & 69,1 & 61,1 & 52,4 \\
\hline Prefixado & 16,1 & 54,8 & 26,4 & 40,2 & 42,7 & 61 & 40,9 & 3,5 & 9,2 & 15,3 \\
\hline Inflação e juros & 5,3 & 33,2 & 52,6 & 35,5 & 14,3 & 11,1 & 8,9 & 6,5 & 5,5 & 10,6 \\
\hline
\end{tabular}

Fonte: 1991 a 1996: Boletim do Banco Central do Brasil, fevereiro de 1997; 1997 a 2000: Relatório do Banco Central do Brasil, 2000.

Neste contexto, a economia do Brasil tem-se caracterizado por baixos níveis de crescimento do PIB e por altas taxas reais de juros, o que suscita a discussão sobre a sustentabilidade do processo de endividamento interno no longo prazo, como discutido, por exemplo, em ROCHA (1997), PASTORE (1997) e TANNER (1995). Esta discussão é pertinente mesmo se considerado o estoque relativamente baixo da divida brasileira em comparação ao PIB quando comparado a outros países (GIAMBIAGI e ALÉM, 1999, p. 153).

O objetivo deste trabalho é verificar os fatores que levaram ao aumento da dívida pública, em uma ótica de curto prazo. Para isto, é desenvolvido um modelo teórico simples da evolução da dívida pública, na seção 2; na seção 3 são apresentados e analisados os resultados empíricos das variáveis para o Brasil, enquanto na seção 4 são analisados cenários alternativos para a dívida pública brasileira. A seção 5 resume as principais conclusões do trabalho.

\section{Modelo de evolução da dívida pública}

Os modelos mais simples dos livros-texto para a dívida pública consideram a economia fechada e, conseqüentemente, levam em conta somente a relação entre dívida pública, déficit primário e juros sobre a dívi$\mathrm{da}$, deixando de lado no primeiro momento qualquer discussão sobre o setor externo. Considerando as contas consolidadas do governo central e do banco central, o comportamento da dívida pública pode ser escrito como: 
$D P_{t}=D P_{t-1}+R O P_{t}+r D P_{t-1}$

onde:

$\mathrm{DP}=$ Dívida Pública Mobiliária Fora do Banco Central

$\mathrm{ROP}=$ Resultado orçamentário primário do governo

$r=$ Taxa real de juros

Claramente, existem situações em que a equação (1) não representa a realidade, quando outras variáveis afetam o valor da dívida. Isto ocorre em situações de renegociação de dívidas dos estados e municípios com o governo federal ou alterações na demanda por moeda. Outra possibilidade é a diferença entre a taxa de juros real esperada quando os títulos são vendidos e a taxa real ex-post, quando já se conhece a inflação ocorrida. Assim, para representar melhor a realidade, a equação (1) teria de ser reescrita em forma de hipótese: $\mathrm{DP}_{\mathrm{t}}=\mathrm{DP}_{\mathrm{t}-1}+\alpha \mathrm{ROP}_{\mathrm{t}}+\beta \mathrm{rDP}_{\mathrm{t}-1}+e_{t}$ onde:

Ho: $\alpha=\beta=1 ; \alpha$ e $\beta$ são coeficientes a ser estimados e $e_{t}$ é o termo de erro.

Quando incluído o setor externo da economia na análise tem de ser considerada a influência da conversão da moeda externa sobre a oferta monetária interna e, dependendo da política monetária adotada pelo governo, possivelmente na dívida mobiliária. De maneira muito restritiva poder-se-ia dizer que

$S E_{t}=\frac{c\left(T C_{t}+B K_{t}\right)}{P_{t}}$

Onde:

$\mathrm{SE}=$ Influência do Setor Externo sobre a liquidez interna

$\mathrm{c}=$ Taxa nominal de câmbio

$\mathrm{TC}=$ Saldo de Transaçōes Correntes

$\mathrm{BK}=$ Saldo da Balança de Capitais

$\mathrm{P}=$ Nível de preços

O modelo da equação (3) seria operacional no caso de não existirem reservas internacionais oficiais, e se todas as transaçōes de residentes com o exterior fossem convertidas em moeda local, ou seja, não houvesse manutenção de ativos de residentes fora do país. Este modelo torna-se ainda menos verossímil quando o governo do país tem transações com o resto do mundo. Isto significa que é possível a ocorrência de variações nas reservas internacionais sem que haja o impacto monetário correspondente. Exemplos deste tipo de transação são emissões governamentais no exterior sem repasse interno ou amortizações 
e pagamentos de encargos sobre a divida externa pública. Por isso, em termos práticos, é de se esperar que

$\mathrm{SE}_{\mathrm{t}} \neq \frac{\mathrm{c}\left(\mathrm{TC}_{\mathrm{t}}+\mathrm{BK}_{\mathrm{t}}\right)}{\mathrm{P}_{\mathrm{t}}}$

Como se está interessado no efeito que as transações com o exterior têm internamente, a melhor alternativa é utilizar a variação da quantidade de moeda em circulação gerada pelas transações com o resto do mundo, o que é medido através do fator condicionante setor externo da base monetária divulgado pelo Banco Central.

O impacto monetário das transações externas da economia tem de ser compatibilizado com os demais objetivos de política econômica, especialmente de controle da inflação, relacionando-se, desta forma, diretamente com a política monetária. A expansão ou contração dos meios de pagamento pela movimentação de recursos monetários do setor externo, por isso, pode ser contrabalançada por outras medidas de política econômica como, por exemplo, operações de mercado aberto. Neste sentido, pode existir uma vinculação entre o comportamento do setor externo como gerador de alterações na base monetária e a dívida pública mobiliária, através do processo de esterilização praticado pelo banco central. Adicionando, então o setor externo à equação (2), obtém-se

$$
\mathrm{DP}_{\mathrm{t}}=\mathrm{DP}_{\mathrm{t}-1}+\alpha \mathrm{ROP}_{\mathrm{t}}+\beta r \mathrm{rDP} \mathrm{t}_{-1}+\gamma \mathrm{SE}_{\mathrm{t}}+\mathrm{e}_{\mathrm{t}}
$$

Subtraindo $\mathrm{DP}_{\mathrm{t}-1}$ de ambos os lados da equação (5), obtém-se a equação

$$
\Delta D P_{t}=\alpha R_{0 P}+\beta r D P_{t-1}+\gamma S E_{t}+e_{t}
$$

Este modelo de evolução da dívida pública será, a seguir, estimado para o Brasil e testada a hipótese nula de que todos os coeficientes sejam iguais à unidade:

Ho: $\alpha=\beta=\gamma=1$.

Se for aceita a hipótese conjunta, significa que a expressão da equação (6) com coeficientes todos iguais à unidade seria uma explicação completa dos determinantes da dívida mobiliária federal. A dívida seria simplesmente a soma da movimentação monetária de três elementos tradicionais da macroeconomia: setor externo, tesouro nacional via seus resultados primários e juros pagos sobre a dívida mobiliária acumulada.

Além da evolução da dívida em valores absolutos, é importante analisar a sua relação com o produto, um indicador do risco que os detentores dos títulos estão correndo, porque a capacidade de paga- 
mento da dívida pelo governo estaria relacionada com a sua arrecadação, e esta arrecadação depende principalmente da renda. Portanto, se a relação dívida/PIB crescer indefinidamente, o risco estará aumentando, tornando o processo ainda mais explosivo pelo aumento dos juros exigido pelos compradores dos títulos. Esta relação, portanto, é acompanhada com muito interesse pelos participantes do mercado. Formalmente,

$D_{t}+j_{t-1}=M_{t}-M_{t-1}+B_{t}-B_{t-1}$

Onde $\mathrm{D}$ é o déficit primário em termos nominais, $\mathrm{j}$ a taxa de juros sobre a dívida $\mathrm{B}$ e $\mathrm{M}$ o estoque de base monetária, todos expressos em valores nominais.

Decompondo a despesa com juros em uma parte correspondente aos juros reais, $r$, e outra à reposição da taxa de inflação, $\pi$, obtém-se

$D_{t}+[(1+\pi)(1+r)-1] B_{t-1}=M_{t}-M_{t-1}+B_{t}-B_{t-1}$

Rearranjando os termos e dividindo pelo PIB nominal $Y_{t}$ obtém-se

$$
\frac{B_{t}}{Y_{t}}-\frac{B_{t-1}}{Y_{t}}=\frac{[(1+\pi)(1+r)-1] B_{t-1}}{Y_{t}}-\frac{\left(M_{t}-M_{t-1}\right)}{Y_{t}}+\frac{D_{t}}{Y_{t}}
$$

Sendo y a taxa de crescimento real do PIB, obtém-se que

$$
Y_{t}=(1+\pi)(1+y) Y_{t-1}
$$

Considerando as relações entre as variáveis e o PIB nominal, $b_{t}=\frac{B_{t}}{Y_{t}}$, $d_{t}=\frac{D_{t}}{Y_{t}}$ e $m_{t}=\frac{M_{t}-M_{t-1}}{Y_{t}}$ e efetuando as substituições, obtém-se

$$
b_{t}-\frac{B_{t-1}}{Y_{t-1}(1+\pi)(1+y)}=\frac{[(1+\pi)(1+r)-1] B_{t-1}}{Y_{t-1}(1+\pi)(1+y)}-m_{t}+d_{t}
$$

Rearranjando os termos e simplificando a expressão, obtém-se que

$$
b_{t}-b_{t-1}=\left(\frac{1+r}{1+y}-1\right) b_{t-1}-m_{t}+d_{t}
$$

Portanto, a variação da relação dívida/PIB depende desta relação no período anterior, da taxa real de juros, da taxa real de crescimento do PIB e das relações entre o superávit primário e o PIB e senhoriagem e PIB. 


\section{O caso brasileiro}

Para testar o modelo da equação (6), os dados do resultado orçamentário primário e do setor externo foram obtidos dos fatores condicionantes da base monetária. Apesar de não ser o conceito usual de déficit público, o impacto do Tesouro Nacional sobre a base monetária tem a vantagem de explicitar a relação da política fiscal com o controle dos agregados monetários pelo Banco Central, tanto em termos de dívida pública quanto da moeda em sentido estrito. O mesmo ocorre com o setor externo, considerando o efeito líquido sobre a oferta de moeda doméstica.

A taxa de juros utilizada (r nas equaçōes (1), (2), (5) e (6)) foi a taxa real, coerentemente com a utilização dos valores da dívida real. A taxa de juros escolhida foi a taxa média de negociação dos títulos públicos prefixados no mercado secundário, a taxa SELIC ${ }^{6}$. Como havia emissão de títulos prefixados e com outros indexadores que não a taxa SELIC, é provável que o custo efetivo da dívida não tenha sido igual àquele medido a partir do mercado secundário. Como estas taxas são resultado de operações efetuadas no mercado financeiro, não se espera que ocorram erros sistemáticos por parte dos participantes, a menos que seja incorporado à remuneração do título um prêmio pelo risco de aumento da inflação ou da taxa nominal de juros quando de sua venda no mercado primário.

A estimação da equação (6) com os dados de 1992 a 2000, entretanto, não apresentou resultados satisfatórios, com um $\mathrm{R}^{2}$ ajustado de apenas 0,39 , como pode ser observado na tabela 2 . Os motivos para este fraco desempenho foram o processo de renegociação das dívidas estaduais e municipais, choque na demanda por moeda e a existência de dívida pública indexada ao câmbio.

Os coeficientes estimados têm os sinais esperados, embora o coeficiente da variável Tesouro Nacional não seja significante. Para melhorar os resultados, a equação estimada foi alterada com a inclusão das seguintes variáveis dummies:

- julho de 1994, quando houve um considerável aumento da demanda por moeda com a queda da inflação;

- dezembro de 1997, renegociação de dívida do estado de São Paulo;

- SELIC significa Sistema Especial de Liquidação e Custódia. Registra as operações com títulos públicos federais. A taxa SELIC é considerada a taxa básica de juros da economia brasileira. 
- outubro de 1998, quando ocorreram renegociações de dívidas com estados da federação e outros ajustes dentro das contas do governo que geraram aumento da dívida pública?.

- janeiro de 1999, quando a alteração do regime cambial brasileiro e desvalorização da moeda doméstica gera um grande aumento da dívida, porque parte da dívida está atrelada à variação cambial.

- março de 1999, quando ocorre uma revalorização da moeda brasileira em relação aos dois meses anteriores.

Tabela 2: Estimativa de DDP - Jan/92 a Dez/00

\begin{tabular}{|c|c|c|c|c|} 
Variável & Coeficiente & Erro Padrão & $\dagger$ & probabilidade t \\
\hline Tesouro Nacional & 0,578 & 0,352 & 1,640 & 0,1039 \\
\hline Setor Externo & 0,738 & 0,172 & 4,303 & 0,0000 \\
\hline Juro real & 1,372 & 0,191 & 7,174 & 0,0000 \\
\hline
\end{tabular}

$\mathrm{R}^{2}=0,39,3$ variáveis e 108 observações.

Tabela 3 - Estimativa de DDP - Jan/92 a Dez/00

\begin{tabular}{|c|c|c|c|c|} 
Variável & Coeficiente & Erro Padrão & + & probabilidade f \\
\hline Tesouro Nacional & 0,515 & 0,185 & 2,782 & 0,0065 \\
\hline Setor Externo & 0,849 & 0,099 & 9,450 & 0,0000 \\
\hline Juro real & 0,996 & 0,118 & 8,442 & 0,0000 \\
\hline Julho 1994 & 35509 & 4757,2 & -7464 & 0,0000 \\
\hline Dezembro 1997 & 56778 & 4806,0 & 11,814 & 0,0000 \\
\hline Outubro 1998 & 22860 & 4955,7 & 4,613 & 0,0000 \\
\hline Janeiro 1999 & 49050 & 4807 & 10,204 & 0,0000 \\
\hline Março 1999 & -27348 & 4822,6 & $-5,671$ & 0,0000 \\
\hline
\end{tabular}

$\mathrm{R}^{2}=0,85,8$ variáveis e 108 observaçōes.

Os resultados apresentados na tabela 3 são consideravelmente melhores que os da tabela 2 . Os coeficientes apresentam os resultados esperados e magnitudes coerentes. Em valores de dezembro de 2000, a remonetização da economia com o plano real gerou uma redução de

7. Cfe. Ministério da Fazenda (1998). 
35,5 bilhões de reais da dívida mobiliária interna, o ajuste da dívida de São Paulo corresponde aproximadamente aos valores renegociados, a desvalorização cambial de janeiro de 1999 gera um aumento da dívida de $R \$ 49$ bilhões e a revalorização em março uma redução de $R \$ 27,3$ bilhões.

No teste da restrição conjunta de que os valores do coeficiente estimado para Tesouro Nacional, Setor Externo e Juros Reais sejam conjuntamente iguais à unidade rejeita-se a hipótese nula de igualdade. Excluindo-se Tesouro Nacional do teste, conclui-se que não é possível rejeitar a hipótese nula de que o coeficiente de Setor Externo e Juros reais sejam conjuntamente iguais à unidade. Isto indica que é possivel admitir que os valores de Setor Externo e Juros refletem-se diretamente na dívida pública interna, o que não ocorre com o Tesouro Nacional.

Este modelo, entretanto, tem a desvantagem de nāo incorporar explicitamente as influências da variação cambial sobre a dívida. Como o Brasil emite títulos cuja remuneração incorpora as variaçōes da cotação do dólar desde pelo menos o começo da década de 1980, este fator não pode ser desprezado, dependendo do contexto de avaliação do risco de desvalorização cambial. A existência de um volume significativo de títulos indexados ao câmbio tem influência no comportamento da dívida, que passa a não ser mais dependente apenas da taxa de juros. O gráfico 1 mostra as participaçōes dos diferentes indexadores na dívida pública mobiliária, em que fica claro a substituição de títulos prefixados por indexados a partir do final de 1997, coincidindo com as turbulências nos mercados financeiros internacionais. $\mathrm{O}$ aumento da participação dos títulos indexados à variação cambial indica a crença na impossibilidade de manutenção do regime cambial, especialmente a partir do segundo semestre de 1998. 


\section{INDEXADORES DA DÍVIDA MOBILIÁRIA}

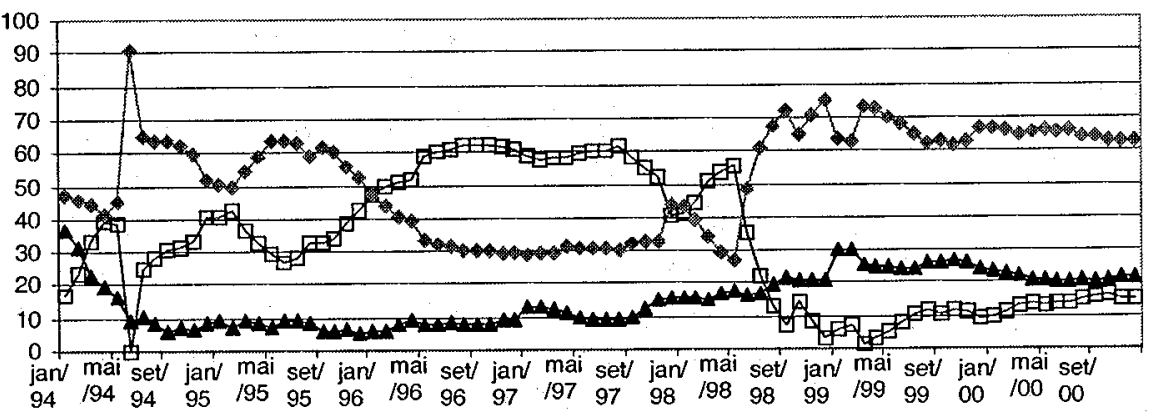

$\multimap$ cambio $\square$ pre $\longrightarrow$ juros e inf

Gráfico 1: Participação percentual dos indexadores na divida pública total

Fonte: Boletimdo Banco Central do Brasil e Notas para a Imprensa.

A inclusão da influência das variações cambiais na dívida pública implica a modificação da equação (6), considerando a parcela da dívida prefixada ou indexada a índices de preços ou juros domésticos, DPC, e a parcela indexada ao câmbio, DPF, cujo custo é f:

$$
\Delta \mathrm{DP}_{i}=\alpha \mathrm{ROP}_{t}+\beta \mathrm{rDPC}_{t-1}+\delta \mathrm{SDPF}_{t-1}+\gamma \mathrm{SE}_{t}+e_{t}
$$

Neste caso, para que a equação opere como uma identidade, ou seja, a variação da dívida é dada pela soma integral desses componentes, tem de ser testada a hipótese conjunta de que os coeficientes $\alpha, \beta$, $\delta$ e $\gamma$ sejam todos iguais à unidade.

O custo da parcela da dívida pública atrelada à variação cambial, f na equação (13), foi obtido a partir da alteração da taxa de câmbio acrescida de uma taxa real fixada arbitrariamente, mas plausível, em 1\%. Para estimar os coeficientes da equação (13), os dados sobre a composição da dívida por indexador só estavam disponíveis a partir de janeiro de 1994. Os resultados desta estimação, apresentados na tabela 4 , são consideravelmente melhores; inclusive para a variável Tesouro Nacional. Por outro lado, a inclusão da influência do câmbio sobre a dívida pública em estimativas que não incluam na amostra os dados a partir de 1999 não se mostrou estatisticamente significante. 
Tabela 4: Estimativa de DDP - Jan/94 a Mai/00

\begin{tabular}{|c|c|c|c|c|} 
Variável & Coeficiente & Erro Padrão & $t$ & probabilidade $t$ \\
\hline Tesouro Nacional & 0,65378 & 0,18034 & 3,625 & 0,0005 \\
\hline Setor Externo & 0,78858 & 0,09234 & 8,540 & 0,0000 \\
\hline Juro real & 1,0980 & 0,13964 & 7,863 & 0,0000 \\
\hline Câmbio & 0,91211 & 0,07075 & 12,892 & 0,0000 \\
\hline Jutho 1994 & -34009 & 4536 & $-7,498$ & 0,0000 \\
\hline Dezembro 1997 & 57083 & 4583 & 12,456 & 0,0000 \\
\hline Outubro 1998 & 22939 & 4706 & 4,874 & 0,0000 \\
\hline
\end{tabular}

$R^{2}=0,8838,7$ variáveis e 84 observações.

O resumo anual dos dados utilizados para a estimação das equações e projeções da dívida é apresentado na tabela 5. Nela é possível ver-se o efeito nitidamente contracionista do Tesouro Nacional e expansionista do Setor Externo sobre a dívida pública. Os juros reais, coerentemente com a ocorrência amplamente dominante de taxas positivas, também contribui para aumentar a dívida pública.

Tabela 5: Determinantes da Dívida Mobiliária Federal (em milhōes de reais de dezembro de 2000 , deflacionados pelo IGP-DI)

\begin{tabular}{|c|c|c|c|c|}
\hline Anos & Tesouro Nacional & Setor Externo & Juro Real $^{\circ}$ & Câmbio $^{\circ}$ \\
\hline 1992 & -6921 & 44835 & 20564 & \\
\hline 1993 & -3037 & 27334 & 11913 & \\
\hline 1994 & -10505 & 24984 & 4039 & \\
\hline 1995 & -6620 & 23314 & 38765 & \\
\hline 1996 & 8394 & 15077 & 33988 & \\
\hline 1997 & -6945 & -12321 & 41000 & \\
\hline 1998 & -20041 & -28397 & 92309 & \\
\hline 1999 & -18696 & -17994 & 15568 & 35573 \\
\hline 2000 & -27508 & 5130 & 19817 & 5114 \\
\hline Total & -91879 & 81962 & 277963 & 40687 \\
\hline
\end{tabular}

a De 1992 a 1998 foi calculado o custo de juros reais sobre o estoque total da divida. Para 1999 e 2000, proporcionalmente à participação do câmbio como indexador e o restante pela taxa de juros real doméstica (over/Selic).

Fonte: Calculado a partir de dados do Boletim do Banco Central do Brasil. 
Utilizando o modelo estimado ${ }^{8}$ e os dados do período, obtém-se como resultado uma previsão para a dívida pública federal em dezembro de 2000 de $R \$ 438,5$ bilhões, aproximadamente $R \$ 50$ bilhōes menor do que a dívida observada em dezembro de 2000. O gráfico 2 mostra a evolução da dívida pelo modelo e a observada. Esta diferença é influenciada pela não inclusão de algumas ocorrências do período, como a devolução dos valores bloqueados pelo Plano Collor em 1990, que se estendeu até 1992, as operações de salvamento de bancos quebrados no âmbito do Proer e toda uma série de ajustamentos de contas dentro do setor público ${ }^{9}$, especialmente estados e municípios, e com o setor privado, os "esqueletos" reconhecidos pelo governo. Levando isto em consideração, a diferença pode ser considerada razoável. Além disso, os dados utilizados referem-se sempre a períodos de mês calendário, não detectando movimentos dentro do próprio mês. Também é necessário considerar que há uma variedade de títulos em circulação com remunerações vinculadas a diferentes indexadores de juros e preços e títulos prefixados, cujas remunerações ex-post não são iguais, como foi simplificadamente assumido.

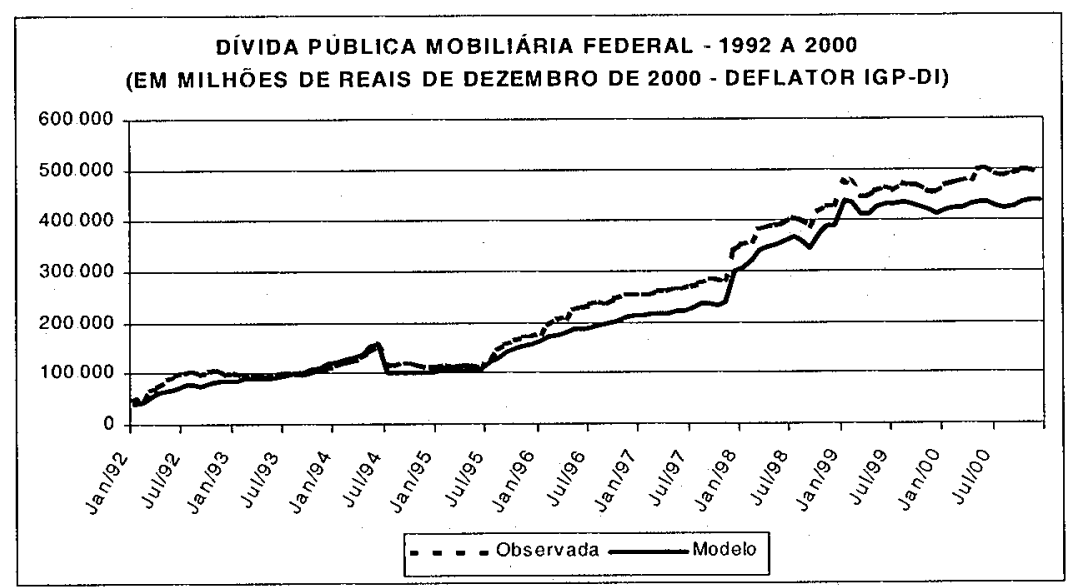

\section{Gráfico 2: Dívida pública mobiliária federal - 1992 a 2000 (em milhões de reais de dezembro de 2000 - deflator IGP-DI)}

\footnotetext{
${ }^{8} \mathrm{O}$ modelo utilizou a equação apresentada na tabela 3 e apenas os custos de juros domésticos (taxa Selic real) até dezembro de 1998 e o custo dos juros domésticos para a parcela da dívida prefixada e atrelada a indexadores que não o câmbio e o custo da variação cambial acrescido de $1 \%$ ao mês para a dívida indexada ao câmbio a partir de janeiro de 1999.

${ }^{9}$ Foram incluídas apenas as ocorrências de julho de 1994, dezembro de 1997 e outubro de 1998 , através de variáveis dummies.
} 
Argumentou-se anteriormente que idealmente a equação (13) deveria operar como uma identidade caso a variação da dívida fosse simplesmente a soma dos componentes, o que indicaria a perfeita adequação do modelo teórico. O teste de Wald para testar a restrição aos coeficientes da equação apresentada na tabela 5, entretanto, rejeita a hipótese nula de que todos os coeficientes sejam iguais à unidade. Retirando-se a restrição à variável Tesouro Nacional, não é possível rejeitar a hipótese de que Setor Externo, Custo de Juros e Custo de Câmbio tenham conjuntamente os coeficientes iguais à unidade ${ }^{10}$. Estas alterações de comportamento do Tesouro Nacional tornam necessário um acompanhamento da variável ao longo do tempo para detectar o que está gerando estas modificações, por suas implicações para a condução da política econômica.

\section{Simulações da evolução da dívida}

Para verificar o comportamento explosivo ou não da dívida pública brasileira, foram calculadas as trajetórias de comportamento da relação dívida pública/PIB para diferentes taxas reais de juros, superávits primários e taxas de crescimento do PIB, como explicitado na equação (12). Não foi adotada distinção entre diferentes remunerações de títulos porque ao longo do tempo não pode ocorrer um diferencial de ganho substancial entre os diferentes critérios de remuneração, pois o próprio mercado as eliminaria através de modificaçōes de cotações dos títulos. Os cálculos efetuados consideram como ponto de partida a relação dívida/PIB de 45,2\% em dezembro de 2000.

Cenário 1: Média observada de resultado primário, taxa real de juros e crescimento do PIB do período 1992 a 2000. Este cenário se apresenta explosivo para a relação dívida/PIB porque as taxas reais de juros têm sido elevadas na história recente da economia brasileira, apesar do considerável superávit primário e taxa positiva de crescimento do PIB.

Cenário 2: Valores observados em 2000 para resultado primário do orçamento, taxa real de juros e crescimento do PIB. Este cenário é favorável em termos da evolução da relação divida/PIB, o que foi pos-

10 Utilizando o período de janeiro de 1992 a novembro de 1997 para estimar o modelo, não é possivel rejeitar a hipótese conjunta de que os coeficientes sejam iguais à unidade. Como este período é anterior aos maiores ajustes dentro do setor público, a mudança de coeficiente do Tesouro Nacional deve estar relacionada a essas renegociaçōes de dívidas. 
sível com um resultado primário muito elevado conjugado com uma taxa elevada para o crescimento do PIB, comparativamente ao observado em anos anteriores. A taxa real de juros também foi relativamente baixa, em função de queda das taxas nominais juntamente com uma taxa de inflação elevada para os padrōes do Plano Real.

Cenário 3: Otimista - Utiliza os melhores resultados de cada variável no período 1992-2000. Mesmo com todas as variáveis com seus melhores desempenhos no período recente, a dívida não consegue ser eliminada. Por outro lado, não é uma combinação muito provável de acontecimentos: elevado superávit, taxa real de juros baixa para os padrōes brasileiros e crescimento de quase $6 \%$ do PIB. Fica evidente neste cenário, como no anterior, a importância da taxa de juros real baixa.

Cenário 4: Pessimista - Utiliza os piores resultados para a dívida no período 1992-2000. Neste cenário a evolução da dívida é extremamente explosiva. A evolução do PIB é levemente negativa, há um pequeno déficit primário, e o principal fator que gera o crescimento da dívida é a taxa de juros real superior a $30 \%$ no ano.

Cenário 5: Considerando a média observada no período de 1992 a 2000 para o resultado primário (superávit de $1,7 \%$ do PIB) e taxa real de juros (16,5\% ao ano), quanto deve crescer o PIB para que a relação dívida/PIB permaneça a mesma? Mesmo que ocorram superávits primários não desprezíveis, a manutenção de taxas de juros reais elevadas exigiria crescimento do PIB de absurdos $12,4 \%$ anuais.

Cenário 6: Considerando a média observada no período de 1992 a 2000 para o resultado primário (superávit de 1,7\% do PIB) e crescimento do PIB (2,9\% ao ano), quanto deve ser a taxa de juros para que a relação dívida/PIB permaneça a mesma? Com a ocorrência de superávit primário e algum crescimento do PIB, a estabilidade da dívida pública pode ser obtida com a redução da taxa de juros para $6,8 \%$ anuais, valor ainda elevado se tomados países desenvolvidos como parâmetro, mas plausível para a economia brasileira, se desconsideradas pressões de curto prazo.

Cenário 7: Considerando a média observada no período de 1992 a 2000 para a taxa real de juros (16,5\% ao ano) e de crescimento do PIB $(2,9 \%$ ao ano), quanto deveria ser o superávit primário para que a relação dívida/PIB permaneça a mesma? Nesta situação, o superávit primário deveria ser de $6 \%$ do PIB, o que exigiria um esforço enorme em termos de aumento da arrecadação e redução de gastos. 
Tabela 6: Comportamento da dívida pública mobiliária - 2001 a 2010

\begin{tabular}{|c|c|c|c|c|c|}
\hline Cenário & $\begin{array}{l}\text { Resultado } \\
\text { Primório } \\
(\% \mathrm{~PB} \mid\end{array}$ & $\begin{array}{l}\text { Taxa real de } \\
\text { Juros }\left(\begin{array}{l}\text { (\%.a. } \\
\text { a }\end{array}\right.\end{array}$ & $\begin{array}{l}\text { Crescimento } \\
\text { do PIB (\% a. a.) }\end{array}$ & $\begin{array}{l}\text { Variacão } \\
\text { divida/PIB }\end{array}$ & $\begin{array}{l}\text { Dívida/PIB em } \\
2010(\%)\end{array}$ \\
\hline 1 & $-1,7$ & 16,5 & 2,9 & 79,6 & 124,8 \\
\hline 2 & $-3,2$ & 7 & 4,5 & $.23,6$ & 21,6 \\
\hline 3 & $-3,2$ & 4,65 & 5,85 & $-35,3$ & 9,9 \\
\hline 4 & 0,9 & 33,4 & $-0,5$ & 849,9 & 895,1 \\
\hline 5 & $-1,7$ & 16,5 & 12,3 & 0,0 & 45,2 \\
\hline 6 & $-1,7$ & 6,8 & 2,9 & 0,0 & 45,2 \\
\hline 7 & $-6,0$ & 16,5 & 2,9 & 0,0 & 45,2 \\
\hline
\end{tabular}

Nestes cenários não foi considerada a receita de senhoriagem que pode ser obtida pelo governo através de aumentos da base monetária. Esta receita depende de taxas de inflaçāo elevadas, em que ela ocorre mesmo que a demanda real por moeda esteja caindo, ou de aumentos da renda que gerem aumentos da demanda por moeda para transaçöes. No caso do crescimento do PIB, o aumento da receita de senhoriagem ocorre no mesmo sentido em que aumentos do PIB reduzem o crescimento da relação dívida/PIB. Por outro lado, taxas de inflação elevadas além de possibilitarem crescimento da receita com emissão de moeda também geram reduções da dívida pública, especialmente se os aumentos de inflação não forem previstos. Neste sentido, a tentação de adotar políticas econômicas que permitam aumentos da inflação é dupla.

Da avaliação dos cenários, conclui-se que o caminho mais factível para controlar o crescimento da dívida mobiliária interna brasileira é a redução das taxas de juros. Ao mesmo tempo, as alterações nas taxas de juros são o instrumento de política econômica mais utilizado nos últimos anos na economia brasileira, tanto em situações de inflação elevada, quanto de inflação baixa. No período anterior ao Plano Real, a taxa real de juros foi mantida elevada para que existisse um prêmio pelo risco de elevação da taxa de inflação, enquanto no período mais recente têm ocorrido elevaçōes nas taxas de juros, quando a economia corre o risco de a inflação aumentar ou em situaçōes de crises externas. Por conseqüência, a redução da taxa real de juros, que seria o principal fator de diminuição do risco de ocorrer um crescimento explosivo da relação dívida/PIB, não apresenta um amplo espaço para 
acontecer. Isto decorre tanto do estrangulamento do setor externo, cronicamente dependente de financiamento quanto pela inexistência de capacidade ociosa generalizada na economia, que impediria o surgimento de focos de pressão inflacionária.

Grandes aumentos do resultado orçamentário primário do governo não são factíveis pelo lado de aumentos da arrecadação, se considerado o quanto o governo está arrecadando a mais em relação ao historicamente observado: a carga tributária era de $24,96 \%$ do PIB em 1992 e passou para $31,67 \%$ em 1999 , mas este é um processo que tem limites. Por outro lado, o superávit pode ser obtido com redução de gastos, o que é politicamente difícil, além de ter efeito contracionista sobre a renda da economia.

Portanto, a estabilidade da relação entre dívida pública e PIB passa pela redução da taxa real de juros, complementada pelo crescimento do PIB e superávit primário no orçamento. A redução dos juros se inter-relaciona com controles da inflação, manutenção do diferencial da taxa de juros interna e externa e financiamento do balanço de pagamentos, que são variáveis importantes no curtíssimo prazo, enquanto o crescimento da dívida é variável que vai se manifestar em prazos mais longos, não tendo impactos imediatos na condução da política econômica, mas sofrendo os impactos desta.

\section{Conclusão}

Os cenários para a dívida pública real evidenciam as dificuldades para a redução da taxa de juros brasileira, embora esta própria taxa elevada seja o principal fator para o crescimento da dívida. O setor externo tem reduzido a sua influência sobre a dívida nos últimos anos. Isto reflete, por um lado, a incapacidade de o país acumular reservas indefinidamente, especialmente a partir do final de $1997 \mathrm{e}$, por outro, a mudança do regime cambial para flutuante a partir de 1999. Comparativamente ao período em que a taxa de câmbio foi rigidamente controlada pelo Banco Central, entre março de 1995 e dezembro de 1998, a volatilidade das reservas internacionais caiu, levando, com isso, à diminuição da necessidade de operaçōes de esterilização com títulos públicos, ou seja, reduz-se a pressão por aumentos da dívida através desse canal.

A política de privatizações futuramente terá pouco efeito sobre a dívida mobiliária, considerando que o tamanho desta é muito maior 
que qualquer soma de privatizações imaginável. O resultado das privatizaçōes federais efetuadas entre 1991 e 2000 foi de aproximadamente US $\$ 47$ bilhões (BNDES, 2000). A maior empresa restante, a Petrobrás, poderá render em torno de US $\$ 18$ bilhões ao governo (RODRIGUES e GIAMBIAGI, 1998).

Ao longo do tempo, a trajetória explosiva da relação entre a dívida pública e PIB pode induzir o devedor, o governo brasileiro, a adotar políticas que levem à redução da dívida, seja através de calote explícito ou disfarçado. Neste sentido, a situação da dívida mobiliária brasileira parece ser uma história que se repete, com o aumento da dívida e posterior redução forçada dos seus valores ${ }^{11}$.

\section{Referências bibliográficas}

BNDES. Privatizações Federais. www.bndes.gov.br. Rio de Janeiro, 2000, consultada em 25/05/2000.

BANCO CENTRAL DO BRASIL. Boletim do Banco Central do Brasil, Brasília, Diversos números.

BANCO CENTRAL DO BRASIL. Relatório Anual do Banco Central do Brasil ed. 2000, Brasilia, 2001.

CORAZZA, Gentil. "Dívida Interna: O Estado Paga a Conta". Ensaios FEE, Porto Alegre, v. 6, n. 2, 1985, p. 171-182.

GIAMBIAGI, Fábio e ALÉM, Ana Cláudia. Finanças Públicas. Rio de Janeiro, Campus, 1999.

PASTORE; Affonso Celso. "Senhoriagem e inflaçāo: o caso brasileiro". In: Economia Aplicada, São Paulo, v. 1, n. 4, out/dez 1997, p. 583-621.

MINISTÉRIO DA FAZENDA - Secretaria do Tesouro Nacional. Notas para a imprensa, disponível em http://www.tesouro.fazenda.gov.br. Consultado em 25/05/ 2000.

ROCHA, Fabiana. "Long-Run Limits on the Brazilian Government Debt". Revista Brasileira de Economia, Rio de Janeiro, v. 51, n. 4, out./dez. 1997, p. 447-470.

RODRIGUES, Adriano Pires e GIAMBIAGI, Fábio. "A agenda de Médio Prazo no Brasil e o Futuro da Petrobrás". In: Revista de Economia Politica, v. 18, n. 3(71), jul/ set 1998, p.100-120.

TANNER, Evan. "Intertemporal solvency and indexed debt: evidence from Brazil, 1976-1991". Journal of International Money and Finance, v. 14, n. 4, 1995, p. 549573.

${ }^{11}$ Cfe. CORAZZA (1985). 